\title{
Políticas judiciárias no Brasil: o Judiciário como autor de políticas públicas
}

\author{
Jeovan Assis da Silva e \\ Pedro de Abreu e Lima Florêncio
}

\section{Introdução}

O propósito deste artigo é focar o papel do Poder Judiciário como formulador de políticas públicas. Em uma incursão de caráter preliminar sobre as especificidades das políticas judiciárias, em comparação com as demais políticas públicas governamentais, buscar-se-á oferecer insumos para um debate ainda incipiente no Brasil sobre o papel do Judiciário como protagonista na elaboração e implementação de políticas públicas em sua própria esfera.

Nos últimos anos, uma produção acadêmica crescente tem enfocado o Judiciário sob o prisma da judicialização da política no Brasil, analisando como e sob quais condições os tribunais influenciam as decisões tomadas no âmbito dos poderes Executivo e Legislativo. Tais estudos destacam a possibilidade de o Judiciário agir no momento da implementação para mudar as regras ou os resultados de políticas públicas concebidas em outras esferas de poder. Contudo, a faceta do Judiciário como elaborador - por iniciativa própria - de políticas públicas, talvez 
por seu caráter recente, parece ainda não ter despertado reflexões mais aprofundadas na área do direito, da política, da sociologia e da administração pública.

A proposta do artigo é salientar a importância de se incorporar o Judiciário no estudo de políticas públicas, uma vez que importantes e inovadoras experiências nesse campo estão ocorrendo na esfera judicial, principalmente em função da criação, em 2005, do Conselho Nacional de Justiça. Este órgão vem desempenhando importante papel de balizador das políticas judiciárias, orientando-as rumo à convergência de propósitos. Tais experiências inovadoras merecem estudos mais aprofundados devido à crescente importância do Poder Judiciário nas sociedades modernas e em função do grande impacto social que geram no funcionamento desse poder e, por consequência, na própria sociedade.

\section{O papel estratégico do Judiciário nos dias atuais}

A visão clássica dos tribunais como instâncias estritamente legais cedeu espaço para o reconhecimento do Judiciário como instituição estratégica nas democracias contemporâneas e que parece ter deixado de se limitar às funções declarativas do direito, passando a se impor como garantidor da cidadania (Sousa Santos, 2007). Em países onde vigora o sistema jurídico de Common Law (modelo anglo-saxão), não é incomum que a implementação de políticas públicas seja discutida nos tribunais. Como nesse sistema as normas legais são, em geral, desprovidas de maiores detalhamentos, o Judiciário desses países está habituado a estabelecer o sentido ou a completar o significado da legislação. Contudo, mesmo em países adeptos do sistema romano-germânico (como Brasil,
Itália e Espanha) onde predominam codificações exaustivas - o que a priori poderia diminuir a necessidade de interpretação pelos tribunais -, o Judiciário é crescentemente chamado a resolver lacunas legais, valorizando a participação do sistema judicial nos processos de políticas públicas.

A positivação dos direitos fundamentais em diversos textos constitucionais nas décadas de 70 e 80 reforçou esse fenômeno e favoreceu sobremaneira a inclusão do Judiciário no espaço da política (Werneck Viana et al., 1999). O Poder Judiciário, atuando no papel de guarda da vontade geral contida nos princípios positivados na ordem jurídica, surge como alternativa importante para a garantia da cidadania, no contexto de uma pauta de facilitação do acesso à justiça. O sistema judicial foi inclusive exposto a formas de interpelação direta de grupos sociais e até de partidos (exemplo das ações diretas de inconstitucionalidade, no caso brasileiro). Juízes tornaram-se guardiões das promessas em um cenário de crescente institucionalização do direito na vida social. Com a decadência do Welfare State, o Judiciário passou a ser percebido como última salvaguarda confiável das expectativas de realização dos ideais de justiça e igualdade. (GARAPON, 2001).

Contudo, o sucesso da Justiça foi inversamente proporcional ao descrédito do Executivo e do Legislativo. Enquanto o Legislativo sofreu os estigmas da deslegitimização de uma comunidade política perdida entre grupos de interesses conflitantes, o sistema judicial também sofreu o impacto de demandas sociais insatisfeitas em um sistema de administração pública que deixava de realizar espontaneamente diversas prestações sociais a seu encargo. 
A efetividade dos direitos sociais no campo do direito - e distante de esferas outrora mais apropriadas - gerou impactos imprevistos sobre o sistema judicial. A própria precarização de direitos econômicos e sociais, a despeito da ampliação do rol de garantias civis e políticas (inclusive em relação aos direitos de terceira geração, como por exemplo, direitos do consumidor), passou a ser motivo de crescente procura do Judiciário pela população, em áreas como educação, saúde, previdência e direito do trabalho.

Alçado à condição de protagonista na esfera pública, o Judiciário logo se viu sobrecarregado com processos e recursos judiciais, deixando de corresponder plenamente às expectativas criadas. Rapidamente a "solução judicial" passou a ser um problema e a transferência de legitimidade estatal do Executivo e do Legislativo para o Judiciário se deu com o correspondente aumento da cobrança social sobre os sistemas judiciais.

\section{As reformas e a criação de conselhos judiciais}

As cobranças em relação ao sistema judicial também emergiram dentro do contexto da globalização econômico-financeira, que se intensificou a partir da década de 1980 e na qual elementos como previsibilidade negocial e cumprimento dos contratos - dependentes de judiciários eficazes e independentes - passaram a ser peças-chave em uma ordem econômica mundial marcada pela competitividade global e pela necessidade de atração de investimentos.

$\mathrm{Na}$ esteira de uma percepção generalizada de crise nos sistemas judiciais de vários países, no final da década de 80 , organismos internacionais como o Banco Mundial e o
Fundo Monetário Internacional passaram a dar especial importância para processos de reformas judiciais na América Latina e na Ásia. O fenômeno, contudo, era certamente percebido como de ordem global, ainda que assumisse matizes distintas e diferentes intensidades de acordo com os locais onde ocorria. Mas apesar de eventuais especificidades, o efetivo acesso à justiça era recorrentemente afetado, sobretudo pela longa duração dos processos, uma vez que

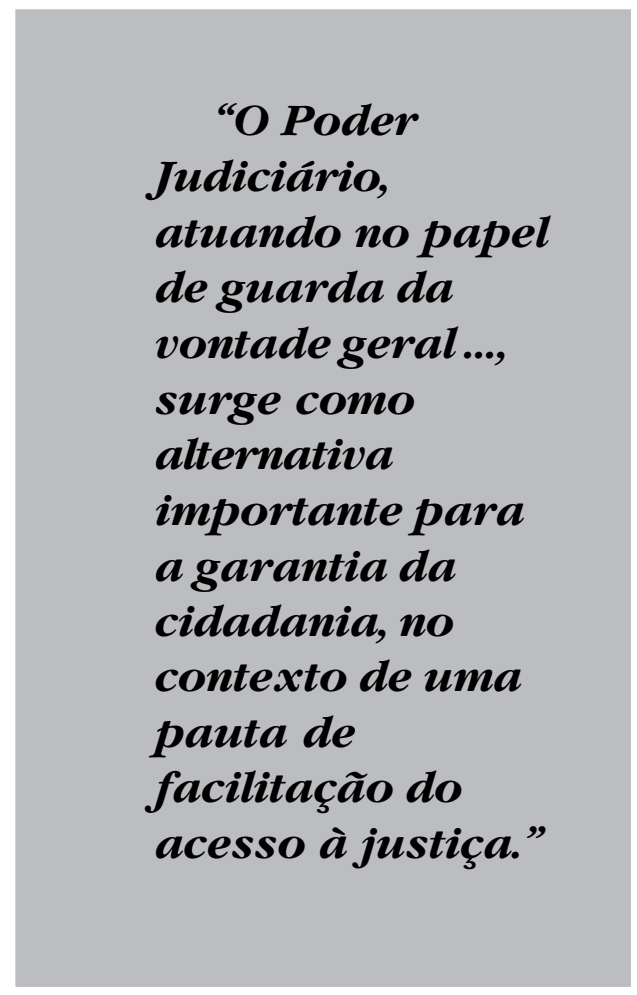

as decisões eram excessivamente demoradas. A morosidade judicial passou a ser reconhecida como um dos problemas mais graves dos atuais sistemas judiciais, com consequentes custos sociais, políticos e econômicos (GOMEs, 2003).

A partir da década de 1990, países como Reino Unido, Itália e Países Baixos experimentaram aproximar o serviço 
judicial dos demais serviços públicos, passando a adotar um foco de gestão pública e abraçando inclusive práticas do New Public Management, como ações de descentralização administrativa e planejamento estratégico. De forma nunca antes vista, os sistemas judiciais europeus passaram a ser cobrados pela efetividade dos orçamentos repassados aos tribunais e questões como ampliação do acesso à justiça e necessidade de reformas processuais e procedimentais também passaram a fazer parte dessas cobranças (FABRi e LANGBROEK, 2000).

No âmbito brasileiro, para além da morosidade, a complexidade estrutural da organização judiciária, a obsolescência administrativa, a ineficiência e a pouca transparência da máquina pública a serviço do Poder Judiciário (Renault, 2005) terminaram por colocar a reforma do Judiciário na agenda política do início do primeiro mandato do Presidente Luís Inácio Lula da Silva. Os desafios dessa reforma eram imensos, pois se pode dizer que no Brasil existem múltiplos judiciários: justiça federal, justiça estadual, justiças especializadas (militar, trabalhista, eleitoral), primeiras e segundas instâncias, tribunais superiores, juizados especiais e etc. Em um sistema de 91 tribunais, há menos de dez anos atrás, prevaleciam a falta de interligação e a desarticulação institucional entre as cortes mesmo diante de uma litigiosidade crescente, comprovada por estatísticas que começaram a ser coletadas de forma sistemática apenas recentemente.

Enquanto no ano de 1990 o Judiciário recebeu 3,6 milhões de processos ${ }^{1}$, no de 2000 esse volume rapidamente ultrapassou o patamar de 20 milhões de ações ingressadas. Ao final de 2009, 25,5 milhões de casos novos (estadual, federal e trabalho) ingressaram no Poder Judiciário e 86,6 milhões de processos encontravam-se em tramitação - casos pendentes somados aos casos novos. $^{2}$

Após anos de intenso debate, iniciado ainda na década de 1990, a respeito de como poderia ser viabilizada a modernização e o controle do Judiciário no Brasil, e de cujas discussões participaram entidades e representantes do segmento jurídico nacional e da sociedade civil, foi enfim alcançado o pacto para a criação do Conselho Nacional de Justiça (CNJ), estabelecido pela Emenda Constitucional n 45 de dezembro de 2004.

Conselhos de justiça remontam ao contexto histórico da Europa pós II Guerra Mundial, tendo a ideia se difundido especialmente em países sem Judiciários autônomos e independentes em matéria administrativa, nos quais a gestão judicial costumava ficar a cargo do Executivo, em órgãos com atribuições similares àquelas exercidas pelo Ministério da Justiça no Brasil. Atualmente, os conselhos judiciais estão amplamente difundidos ao redor do mundo, ainda que assumam diferenciados formatos institucionais de acordo com os ajustes necessários para cada sistema judicial nacional. Exemplos importantes ao redor do mundo, ainda que as atribuições variem bastante, são encontrados nos EUA, França, Itália, Holanda e Reino Unido. Os conselhos judiciais parecem responder às diferentes pressões por accountability existentes nos judiciários nacionais e refletem os diferentes contextos sociais (GAROUPA e GinsBurG, 2008).

No contexto latino-americano, conselhos de justiça criados nos anos 70, sob diretrizes de regimes autoritários, tiveram o papel de limitar a atuação do Poder Judiciário e controlar correcionalmente suas atividades. Com a transição para a democracia, esses conselhos foram extintos 
ou tiveram sua competência alterada (Argentina, Bolívia e México). Talvez por isso, a criação do CNJ tenha enfrentado muita resistência, a partir da memória do extinto Conselho Nacional da Magistratura, que vigorou entre 1977 e 1988 e que tinha caráter estritamente disciplinar. Esse antecedente certamente prejudicou a discussão acerca de uma instituição voltada para o controle e coordenação da administração judicial.

A partir da década de 1990, entretanto, percebeu-se que em ambiente federativo, com tribunais estaduais dotados de autonomia e capacidade de auto-organização, o Brasil não poderia mais prescindir de políticas racionais e coordenadas para o enfrentamento dos problemas sistêmicos do Judiciário, o que implicaria a criação de um órgão de planejamento nacional que editasse normas gerais de organização, coordenação e comunicação do sistema judicial.

Sob tais premissas foi criado o CNJ, tendo inclusive, que superar um debate sobre sua constitucionalidade logo após sua instalação. A instituição tem se consolidado como órgão central de planejamento do Judiciário, com vistas a uniformizar procedimentos e metas, racionalizar a prestação jurisdicional e aperfeiçoar o acesso à justiça, para além do seu papel como instância de acompanhamento disciplinar. Apesar de sua breve existência, o CNJ tem se firmado como um importante ator do sistema judicial, na medida em que a definição e a implementação de políticas judiciárias, conforme veremos mais adiante, constituem um dos aspectos essenciais de sua atuação.

\section{Judiciário e políticas públicas}

As questões referentes à modernização do Judiciário só passaram a ser consideradas questões de Estado muito recentemente. Durante muitos anos, não havia o envolvimento dos agentes públicos e dos outros poderes com as questões relativas ao sistema judicial, que inclusive chegou a ser compreendido como the least dangerous branch ${ }^{3}$ dentre as esferas de poder. Mas de assunto de interesse restrito dos magistrados e suas entidades de classe, o Judiciário tornou-se objeto de amplo escrutínio social e seus problemas alcançaram relevância jamais vista.

Por um lado, a decadência das políticas públicas típicas dos Welfare States no mundo e a consequente redução de vários programas de cunho social, anteriormente disponibilizados por meio do Executivo, aumentaram o número de ações que chegaram ao Judiciário clamando por esses benefícios. Por outro, a importância deste poder enquanto instituição garantidora de um ambiente propício às operações econômicas e ao clima negocial, reduzindo o custo de transações e contribuindo para resultados economicamente mais eficientes, ganha relevância crescente. ${ }^{4}$

Nesse sentido, aponta-se recorrentemente a credibilidade institucional como requisito de relevo para estratégias sustentáveis de desenvolvimento, conforme fica evidente nos recentes programas do Banco Mundial para os países em desenvolvimento, especialmente aqueles voltados para o fortalecimento dos seus sistemas de justiça. Tal transformação do Poder Judiciário é uma questão-chave para se compreender a incursão do sistema judicial na seara de políticas públicas, especificamente voltadas para o aperfeiçoamento da prestação jurisdicional.

Sabe-se que, dentre outras possibilidades, um determinado tema pode se converter em um problema público - e passar a fazer parte da agenda de atuação 
dos poderes públicos - quando a questão tenha alcançado proporções de "crise" e não possa mais deixar de ser ignorada. Outra possibilidade é quando suscita questões relacionadas à legitimidade, afetando o núcleo sensível do poder público e envolvendo grande carga simbólica (SubIRATS, 2007). No caso brasileiro, a crise no sistema de justiça não é um fenômeno recente. Pesquisas mostram que, ao menos quanto à eficiência do Judiciário, no que diz respeito ao tempo e a burocratização de seus serviços, sua legitimidade vem sendo questionada desde o início da década de $1980 .^{5}$

A despeito da crescente atenção deslocada para o Poder Judiciário, ainda não é estudado na dimensão necessária, principalmente no tocante à sua importância na efetividade de importantes políticas públicas (TAYLOR, 2007), até porque existiriam pelo menos três dimensões de atuação relevante dos tribunais para a ciência política, quais sejam: a hobbesiana, a smithiana e a madisoniana. ${ }^{6}$ Observa-se que os estudos sobre o Judiciário ainda se restringem excessivamente à dimensão hobbesiana $\mathrm{da}$ segurança pública ou ao campo smithiano, cuja ênfase recai sobre os custos e incentivos à economia de mercado (CASTELAR Pinheiro, 2000). Pouca atenção, portanto, tem sido dada para a dimensão madisoniana de interrelação entre os poderes, principalmente no que diz respeito às políticas públicas. Nesse sentido, uma faceta de atuação do Judiciário relativamente ignorada refere-se ao seu papel como formulador de políticas públicas direcionadas especificamente para esse poder.

Nesta primeira década do século XXI, é alvissareiro constatar crescente grau de mobilização institucional para a busca de soluções aos problemas do Judiciário, com base no entendimento de que políticas públicas especificamente orientadas para o sistema judicial são relevantes para o próprio aperfeiçoamento da democracia. Experiências importantes foram realizadas no contexto do primeiro e do segundo Pacto Republicano (2004 e 2009, respectivamente), que representaram atos conjuntos dos Poderes Executivo, Legislativo e Judiciário com vistas, sobretudo, a alterações legislativas urgentes para a modernização do sistema de justiça. Contudo, tais modificações legais, para serem efetivas, precisam estar acompanhadas de políticas públicas que realmente possam garantir o alcance dos objetivos pretendidos.

Para fins do presente artigo, apesar de inexistir um "conceito jurídico" de políticas públicas, cabe destacar que algumas definições ressaltam a interveniência de um conjunto de processos, inclusive o judicial, no que tange às ações de governo, de modo que se pode definir política pública como "o programa de ação governamental que resulta de um processo ou conjunto de processos juridicamente regulados - processo eleitoral, processo de planejamento, processo de governo, processo orçamentário, processo legislativo, processo administrativo, processo judicial” (Bucci, 2006).

Nas últimas décadas, tem-se reconhecido a possibilidade de interveniência judicial no processo de construção de políticas públicas, muitas vezes no âmbito da chamada "judicialização da política", cujos reais alcance e significado ainda são objeto de grande debate no meio acadêmico. A princípio, tal fenômeno indicaria os efeitos da expansão do Poder Judiciário no processo decisório das democracias contemporâneas, principalmente quando os tribunais são chamados a se pronunciar onde o funcionamento do Legislativo e do 
Executivo se mostra falho, insuficiente ou insatisfatório (CASTro, 1997). Contudo, no atual contexto de mudanças sociais que embaralham as relações entre direito, política e sociedade, o termo acabou por adquirir múltiplos significados ${ }^{7}$, os quais decorrem dos diferentes entendimentos sobre o papel do Judiciário na democracia brasileira.

Compartilhando a compreensão de que há espaço para recortes mais específicos para o estudo do papel das instituições judiciais no Brasil contemporâneo (MAciel e Koerner, 2002), a proposta aqui apresentada é a de frisar a possibilidade de atuação do próprio Poder Judiciário na conformação e implementação de políticas públicas. Parte-se do entendimento de que as políticas públicas devem ser entendidas como ações estatais voltadas a tornar concreta a atuação dos conteúdos normativos constitucionais que norteiam as decisões políticas, não sendo exclusivas de um poder ou outro.

Ressalte-se que outras concepções de política pública designam não somente a política do Estado, mas também políticas voltadas para fazer avançar objetivos coletivos de aprimoramento social e que, ao estabelecer metas e os caminhos para a consecução destas, podem vincular além dos órgãos estatais, também agentes econômicos e a sociedade civil (MASSA-ARZBABE, 2006). Nessa abordagem finalística, as políticas públicas cada vez mais interagem com a ideia de governance ou governança, conceito amplo que envolve a proteção dos direitos dos cidadãos, a base legal apropriada à busca do progresso econômico e social, as condições indispensáveis à atuação do setor empresarial, a alocação eficiente e eficaz de recursos públicos. Inclui ainda a observância de padrões de responsabilidade, ética e transparência em todas as esferas da gestão pública (CunHA, 2010). O conceito de governança também remete às estruturas de organização e gestão do poder, nos quais a ação pública (construção de problemas públicos, das soluções e de suas formas de implementação) passa necessariamente pela coordenação de múltiplos níveis e atores.

A existência de "políticas públicas judiciais" já tem sido reconhecida e definida como a identificação, mobilização e coordenação de recursos públicos

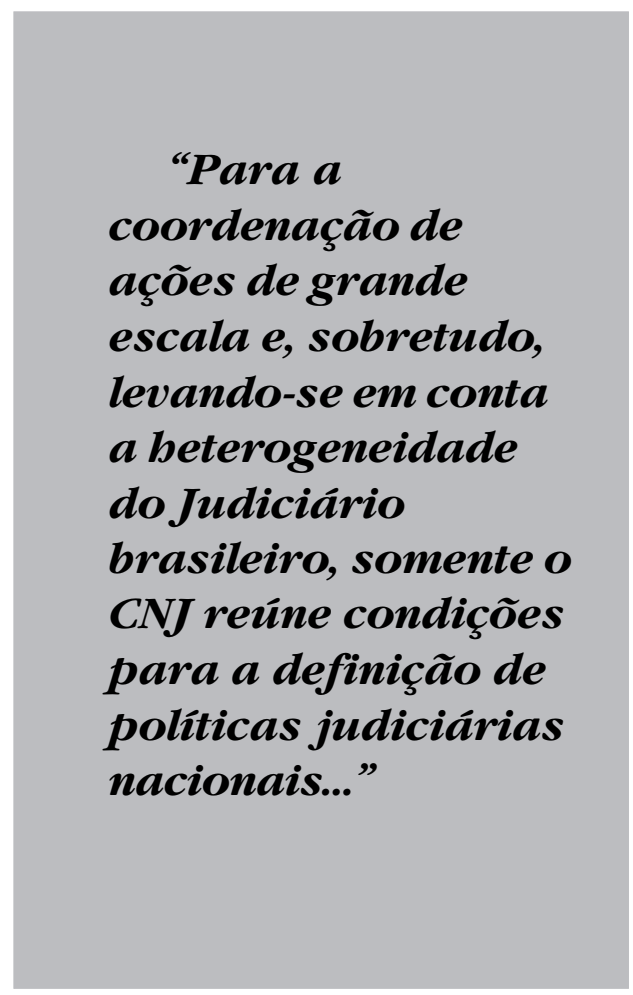

institucionais, financeiros, humanos ou legais em favor da reforma do Judiciário (FALCÃO, 2006). O papel relevante do CNJ no planejamento e na implementação de "políticas judiciais" também tem sido reconhecido, na medida em que sua razão de ser institucional seria pensar o sistema de justiça nacional como uma estrutura integrada (RENAULt, 2005). 
Uma vez que o processo de identificação de uma tipologia própria de "políticas públicas judiciais" ou "políticas judiciais" já teve início, entende-se que também seria oportuno para o melhor delineamento do fenômeno específico, o Judiciário avocar para si políticas públicas inerentes à própria máquina judicial, atuando inclusive no sentido de implementá-las, seja de forma singular ou com a participação de outros atores governamentais.

Para começar, preferir-se-á buscar compreender o fenômeno a partir da expressão "políticas judiciárias", porque entende-se aqui que o uso do termo políticas judiciais pode equivocadamente remeter ao que, em inglês, corresponde à expressão "judicial policies". Nos EUA, os estudos sobre judicial policies enfatizam o impacto que as decisões de cortes superiores possuem sobre cortes inferiores ou mesmo sobre o pronunciamento judicial a respeito de políticas públicas implementadas nas demais esferas de governo (bons exemplos seriam as decisões a respeito de ações afirmativas e aborto). Políticas judiciais também surgiriam quando magistrados tomam decisões políticas a partir da interpretação da Constituição ou da elaboração de precedentes judiciais. No contexto das políticas judiciais nos EUA, os tribunais são percebidos como importantes integrantes do sistema político e capazes de iniciar e modificar políticas públicas.

Uma vez que o presente artigo não aborda a função política dos tribunais, salientamos desde logo a distinção de que as judicial policies, no caso norte-americano, não são implementadas por si só, uma vez que em geral requerem atores não judiciais para implementar as políticas em questão (Cannon e Johnson, 1998). No entendimento de políticas judiciárias deste estudo, vislumbra-se a possibilidade de que elas possam contar com a participação de atores não judiciais. Porém, via de regra, considera-se que são como políticas geradas e implementadas pelo próprio Judiciário, podendo inclusive abranger todas as etapas do ciclo da política pública.

Propõe-se, no presente artigo, a definição de políticas judiciárias como o conjunto de ações formuladas e implementadas pelo Poder Judiciário em sua própria esfera para o aprimoramento de sua atuação e efetivo exercício de suas atribuições. As políticas judiciárias ocorrem a partir da identificação, análise e diagnóstico dos problemas que afetam a função jurisdicional do Estado, podendo abranger, entre outros aspectos: a definição de normas; a articulação de recursos humanos, financeiros e tecnológicos; a fixação de metas, diretrizes e estratégias para o tratamento da litigiosidade; a implementação de soluções e filtros pré-processuais; a modernização da gestão judicial; a coleta sistemática de dados estatísticos; a avaliação permanente do desempenho judicial; a efetivação racional do acesso à justiça; e a análise e o estudo de propostas de reformas e modificações processuais para o aperfeiçoamento da prestação jurisdicional.

Como se pode observar, em razão de suas especificidades, as políticas judiciárias seguem rumos próprios e distintos dos arranjos por outras áreas de políticas públicas governamentais tradicionais (saúde, educação, trabalho, previdência etc) porque envolvem um aparelho judicial que se comporta de forma bastante diferenciada de outros serviços públicos. E também porque o Judiciário frequentemente é a última parada onde muitos conflitos sociais desembocam após não terem sido devidamente tratados em outras esferas (sobretudo nas áreas cível e criminal), assim como 
é o ponto de partida de uma trajetória judicial ainda marcada pelo uso escasso de alternativas de acordo ou conciliação. De modo também relevante verifica-se que, no Brasil, poucos usam o Poder Judiciário em demasia - os grandes e recorrentes litigantes são do setor público e privado ${ }^{8}$, ao passo que grande parte da população ainda não tem acesso aos modos de acionamento do sistema judicial.

No âmbito do estudo das políticas judiciárias propõe-se analisar o Poder Judiciário sob a ótica da realidade e das peculiaridades dessa esfera de governo. $\mathrm{O}$ desenho, a implementação e a avaliação de políticas judiciárias são pontos-chave para o gerenciamento efetivo dos tribunais. Isso implica que os tribunais devem coletar sistematicamente informações sobre o próprio desempenho e sobre as necessidades dos jurisdicionados. Mas para além da coleta de dados, as cortes precisam fazer com que as informações obtidas sejam efetivamente utilizadas em prol do aperfeiçoamento dos seus serviços.

Reconhece-se aqui que as referidas políticas podem e devem ser concretizadas por tribunais de modo individualizado, o que inclusive contribui para a incorporação de elementos locais ou específicos de cada ramo da justiça, com vistas a uma maior qualidade dessas políticas. A possibilidade de relativo grau de autonomia financeira em alguns estados, em virtude do recolhimento da taxa judiciária, somente reforça a independência e a possibilidade de o Judiciário desenvolver ações concretas de melhoria da tutela jurisdicional e de formulação de políticas públicas de atendimento eficiente. No entanto, esse conjunto de políticas localizadas demanda coordenação e o estabelecimento de diretrizes comuns que as congreguem rumo a objetivos que perpassam todo o Poder Judiciário.
Para a coordenação de ações de grande escala e, sobretudo, levando-se em conta a heterogeneidade do Judiciário brasileiro, somente o $\mathrm{CNJ}$ reúne condições para a definição de políticas judiciárias nacionais, conforme veremos a seguir.

\section{O papel do $\mathrm{CNJ}$}

A aprovação da Emenda Constitucional n $n^{\circ} 45 / 2004$ deve ser recebida como o primeiro grande passo para a modernização do sistema judicial brasileiro (COSTA, 2009), principalmente porque viabilizou a criação de novo modelo de exercício de autogoverno e controle do aparelho judiciário. O Conselho Nacional de Justiça emergiu como o instrumento institucional mais adequado para o avanço de políticas específicas para o Poder Judiciário, seja pelo seu rol de competências, seja por representar os inúmeros ramos do sistema judicial e a sociedade civil, o que confere às suas decisões legitimidade democrática. Qualquer cidadão ou pessoa jurídica pode se dirigir ao $\mathrm{CNJ}$, o que na prática tem-se traduzido em grande pluralidade e representatividade dos que nele demandam, desde partes em processos judiciais a entidades de magistrados, de advogados e da sociedade civil, além de parlamentares e organismos governamentais.

O Conselho Nacional de Justiça é composto por 15 membros (nove magistrados, dois membros do Ministério Público, dois advogados e dois cidadãos indicados pelo Congresso Nacional), sendo presidido pelo presidente do Supremo Tribunal Federal. As competências do CNJ, nos termos do art. 103-B da Constituição Federal, relacionam-se com os seus objetivos em termos do planejamento estratégico, do controle administrativo e da responsabilidade 
disciplinar de magistrados e servidores da justiça. Além de se organizar de forma plenária, e no âmbito de grupos de trabalho ad hoc, o CNJ trabalha por meio das seguintes comissões em sua atual composição (2009-2011): Comissão de Relacionamento Institucional e Comunicação; Comissão de Gestão Estratégica, Estatística e Orçamento; Comissão de Acesso à Justiça e à Cidadania; Comissão de Eficiência Operacional e Gestão de Pessoas; e Comissão de Tecnologia da Informação e Infraestrutura.

Os conselhos de políticas públicas, objeto de recente estudo pela ciência política, inserem-se fundamentalmente na área da governança democrática, tendo poder de agenda e definindo diretrizes de políticas que caminhem no sentido da equidade e da efetividade (CArneiro, 2007). Além de propiciar maior grau de accountability e legitimidade às políticas públicas, os conselhos trazem alianças e conflitos de interesse para esferas públicas de decisão, permitem maior grau de acerto nos processos de tomada de decisão, bem como ajudam na identificação mais rápida de problemas e na construção de alternativas de ação.

Ainda que não assuma propriamente o formato e o modus operandi de outros conselhos de políticas públicas (ou conselhos gestores de políticas setoriais, como os Conselhos de Saúde, Assistência Social, de Direitos da Criança e do Adolescente) existentes no âmbito federal, estadual ou municipal, podemos identificar similitudes do CNJ com esses fóruns, na medida em que constitui um colegiado permanente, deliberativo, com caráter de supervisão, presença de representantes da sociedade civil, bem como encarregado de responsabilidades no que tange a políticas públicas.

Ainda que seja mais reduzido e não tenha caráter paritário de outros conselhos de políticas públicas, defende-se aqui que o órgão também constitui uma inovadora modalidade de controle público sobre a ação governamental e, idealmente, de corresponsabilização quanto ao desenho, monitoramento e avaliação de políticas públicas. Também se pode enfatizar o caráter participativo do Conselho na definição de políticas judiciárias, tanto por seu próprio caráter colegiado quanto pelo fato de suas ações relacionadas à realização de:

1) Audiênciaspúblicas: no período 20082010, mais de 2 mil pessoas de diferentes estados brasileiros se manifestaram em relação ao funcionamento da Justiça, seja publicamente, nas audiências públicas, seja em particular, por meio dos atendimentos individuais. Demoras no andamento de processos, denúncias de irregularidades e casos de nepotismo foram alguns dos principais problemas apontados.

2) Inspeções: até o momento, já realizadas em mais de 17 unidades da federação, as inspeções propiciam um verdadeiro retrato do Judiciário brasileiro em suas distintas localidades e ramos, evidenciando as deficiências encontradas, bem como trazendo à tona boas práticas passíveis de compartilhamento por outros tribunais. Ao final de cada inspeção, um relatório é produzido e o CNJ tem fiscalizado e avaliado o cumprimento das recomendações realizadas.

3) Planejamento estratégico e metas: antes de 2008, iniciativas de planejamento estratégico eram apenas pontuais e jamais havia sido realizada uma reunião nacional de presidentes de tribunais. A partir de 2009, o trabalho do Conselho passou a ser norteado por metas anuais com vistas a torná-lo menos moroso, mais eficiente, moderno e ao alcance do cidadão. A meta $\mathrm{n}^{\circ}$ dois de 2009, que consistia na identificação 
e julgamento de todos os processos judiciais distribuídos até $31 / 12 / 2005$, foi um marco no início de um comprometimento do Judiciário em adotar uma postura mais proativa em prol da redução da morosidade.

A realização de audiências públicas e inspeções, com participação dos cidadãos, bem como a adoção de métodos de planejamento participativos, conferem caráter especial às políticas do CNJ, já que maiores graus de participação social agregam maior quantidade e qualidade de informações para a tomada de decisões e a definição de políticas pelo colegiado.

Apesar de seu breve período de existência, um amplo rol de políticas tem sido concebido e discutido no âmbito do órgão para incrementar a atuação do Poder Judiciário, mitigando problemas crônicos que o afligem, tornando-o cada vez mais efetivo, célere e responsivo às necessidades sociais. Destacam-se, nesse sentido, as discussões operadas para as regulamentações da súmula de efeito vinculante e da repercussão geral no Recurso Extraordinário, que reduzem as possibilidades de uso repetido e abusivo do sistema judicial e diminuem a elevada carga de trabalho dos ministros do Supremo, permitindo que se concentrem em questões de maior relevância e impacto social. Outro avanço digno de nota foi a criação da súmula impeditiva de recursos que visa racionalizar a sistemática dos recursos judiciais e evita a utilização da Justiça para fins exclusivamente protelatórios.

No plano das ações operadas diretamente pelo CNJ ressalta-se, primeiramente, a elaboração do planejamento estratégico do Poder Judiciário, disciplinado pela Resolução n 70 doConselho. Por meio do planejamento estratégico espera-se que os órgãos do Poder Judiciário possam atuar com um norte comum, munidos pelos mesmos princípios e propósitos, implementando ações convergentes com objetivos semelhantes. O planejamento estratégico propõe-se a dar direcionamento a todos os órgãos da justiça, evitando que atuem de maneira excessivamente isolada, sem comunicação. Soluções particulares e específicas, sem visão sistêmica na maioria das vezes, levam a desperdícios e a retrabalho.

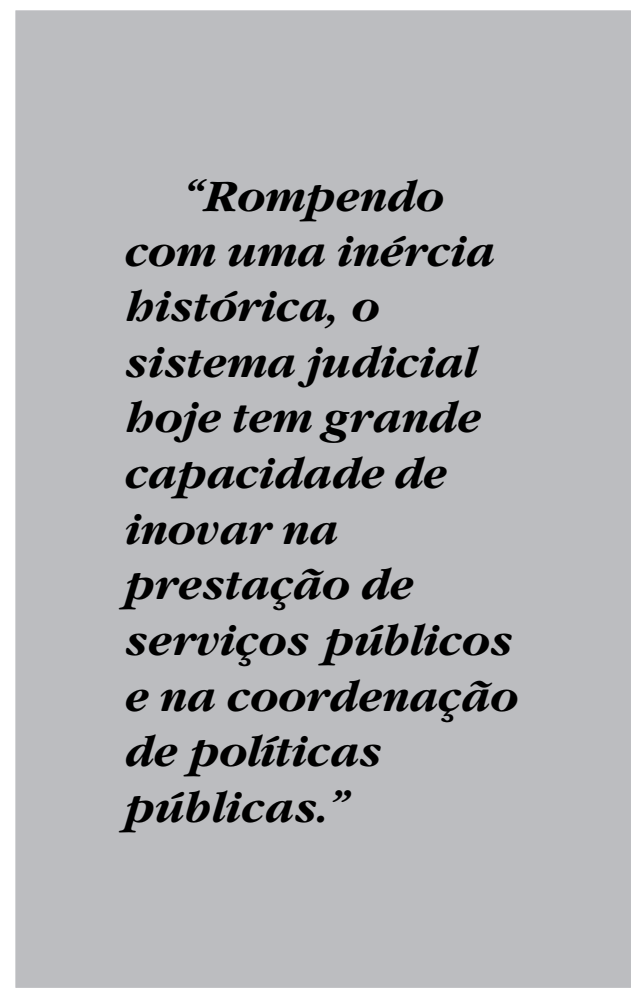

Nos Encontros Nacionais do Judiciário, dentro da lógica do planejamento estratégico e do estabelecimento de objetivos pelos órgãos jurisdicionais, os tribunais brasileiros traçam metas de nivelamento para serem atingidas anualmente, de modo a proporcionar maior agilidade e eficiência à tramitação dos processos, melhorar a qualidade do serviço 
jurisdicional prestado, bem como ampliar o acesso do cidadão brasileiro à justiça. Essas metas são democraticamente debatidas e consensualmente estipuladas com representantes dos 91 tribunais brasileiros.

Todos esses objetivos de políticas públicas e de planejamento estratégico só fazem sentido, porém, caso possam contar com indicadores de cumprimento de metas passíveis de contínuo monitoramento. É por essa exata razão e também para se estimular o controle social e a transparência no Judiciário que o $\mathrm{CNJ}$ preconizou o desenvolvimento de indicadores estatísticos para avaliar o sistema de justiça no Brasil a partir de 2004. Desenvolveram-se, nesse sentido, dois sistemas estatísticos nacionais no âmbito da justiça brasileira: o Justiça em Números e o Justiça Aberta, e implementou-se um projeto com o objetivo de incrementar a consistência e promover a padronização dos dados processuais obtidos: a Padronização Taxonômica das Tabelas Básicas de Classes, Movimentações e Assuntos.

Ainda no âmbito das mudanças procedimentais com alto impacto na prestação jurisdicional existe o "Programa Integrar", que proporciona auxílio aos tribunais de justiça na adoção de um modelo de gestão moderno, com base nos princípios da administração pública gerencial. Pretende-se, assim, adequar as metas do Planejamento Estratégico do Judiciário Nacional à realidade local, por meio das adaptações específicas que se façam necessárias. No âmbito dos programas de modernização, destacam-se também as iniciativas do CNJ para a informatização plena de todos os órgãos da Justiça no País, por meio de ações coordenadas de aquisição, manutenção, revisão e implantação de soluções de tecnologia da informação.
No tocante às ações para garantir maior celeridade e efetividade aos mecanismos de execução das sentenças no Judiciário, destacam-se o Infojud, o Bacenjud e o Renajud. O sistema Infojud permite a esse Poder fazer requisições judiciais de informações protegidas por sigilo fiscal, bem como a obtenção segura e ágil das respostas por via eletrônica. O Bacenjud é um sistema seguro e econômico que permite aos juízes, de posse de uma senha previamente cadastrada, enviar ordens judiciais ao Sistema Financeiro Nacional, reduzindo-lhes, assim, o tempo de tramitação. Já o Renajud possibilita que juízes possam consultar, em tempo real, a base de dados sobre veículos e proprietários do Registro Nacional de Veículos (Renavam), inserindo restrições judiciais de transferência, licenciamento e circulação, bem como registro de penhora sobre os veículos.

Qualquer projeto bem estruturado de melhoria do Poder Judiciário, no entanto, não pode estar somente focado em ações gerenciais e de incrementos procedimentais para dar vazão aos litígios de maneira mais eficiente. É por essa razão que o Conselho se preocupa com a redução das lides por meio do estímulo às soluções alternativas de controvérsias, como a mediação e a conciliação. O "Movimento pela Conciliação" foi criado pelo órgão em 2006, como fruto dessa preocupação, e consolidou-se com a Recomendação CNJ n 8 de 2007, que sugere aos Tribunais de Justiça, Tribunais Regionais Federais e Tribunais Regionais do Trabalho a realização de estudos e de ações tendentes a dar continuidade a programas de incentivo à conciliação. Mais recentemente fixaram-se prazos para os tribunais instalarem centrais de conciliação, cabendo ao Conselho: auxiliar os tribunais na organização dos trabalhos; firmar parcerias com entidades 
públicas e privadas para o desenvolvimento de ações que auxiliem a conciliação de processos; desenvolver conteúdo programático e ações voltadas para a capacitação, em métodos consensuais de solução de conflitos, por parte dos servidores, mediadores e conciliadores.

Outras iniciativas importantes referemse a assuntos como mutirões carcerários, atendimento judicial para a infância e juventude, necessidade de uniformização de custas judiciais, entre outros. Portanto, são várias as ações, nas mais diversas áreas, levadas a termo pelo CNJ, com o objetivo de contribuir para uma justiça mais ágil, transparente e efetiva. Todas essas incursões gerenciais, procedimentais e de autoconhecimento do Poder Judiciário contribuem para o aperfeiçoamento operacional da Justiça e para maior segurança jurídica, que pressupõe a aplicação previsível e transparente das normas e regras .

Nesse cenário, o Conselho tem um papel fundamental a desempenhar. $\mathrm{O}$ órgão favorece a institucionalização não só de novas concepções do trabalho judiciário, mas também a própria interferência nas causas de problemas estruturais que afetam todo o sistema judicial brasileiro. Mas, para enfrentar essa realidade, é necessário não somente analisar os aspectos relativos à estrutura dos órgãos Judiciários e de como processam os litígios e os administram, mas também urge questionar como as demandas judiciais formam-se e se desenvolvem, até se consolidarem, algumas, como demandas de massa, com enorme potencial de congestionamento do sistema. Somente com uma visão sistêmica e dinâmica poder-se-á identificar onde residem os gargalos, as inoperâncias, os conflitos latentes e, assim sendo, fazer as corretas sugestões de políticas judiciárias.
Para além do seu papel de formulação e implementação dessas políticas, apresenta-se ao CNJ o grande desafio de coordenação de ações no multifacetado Judiciário brasileiro. Espera-se que, apesar de sua instalação recente, o Conselho saiba conter excessos de ativismo institucional por meio do estabelecimento de prioridades e logre evitar a sobreposição de ações. Superados os momentos iniciais de definição de sua missão e inserção política, o órgão precisa estar coeso para realmente garantir maior grau de racionalidade e organicidade às políticas judiciárias.

A coordenação de ações na pluralidade da justiça brasileira envolve o aprofundamento do diálogo com os mais diversos atores do sistema judicial. Nesse contexto, o CNJ deve permanentemente liderar um processo de concentração de diversos interesses em torno de objetivos comuns, o que significa driblar forças conservadoras, assim como superar resistências e atitudes corporativistas que inevitavelmente reagem aos esforços de modernização em curso.

\section{Conclusão}

O presente artigo ressalta o urgente imperativo de se aprofundar a análise e o debate críticos sobre os fundamentos, dinâmica, construção institucional, limites e potencialidades dos processos subjacentes à formulação e implementação de políticas judiciárias. O Judiciário constitui hoje importante locus de políticas públicas merecendo receber, portanto, maior atenção dos gestores públicos e dos cientistas políticos e sociais. Rompendo com uma inércia histórica, o sistema judicial hoje tem grande capacidade de inovar na prestação de serviços públicos e na coordenação de políticas públicas. 
A consolidação das políticas judiciárias tem o potencial de transformar as feições tradicionais da justiça no modo de se relacionar com a sociedade e de exercer seu papel protagonista e estratégico de forma mais responsiva. Nesse cenário, defendese que somente o $\mathrm{CNJ}$ poderia garantir a sustentabilidade de políticas judiciárias de cunho nacional sem se perderem em meio à multiplicidade do Judiciário brasileiro. $\mathrm{O}$ enraizamento e a coordenação dessas políticas em um órgão central reforçam a possibilidade de ações de longo prazo, com grandes repercussões sobre a eficiência, eficácia e efetividade da prestação jurisdicional. O Conselho, uma vez dotado de diagnósticos precisos e de uma interlocução/atuação efetiva junto aos tribunais, poderá assegurar no futuro uma qualidade básica uniforme e nacional para os serviços judiciais.

(Artigo recebido em abril de 2011. Versão final em agosto de 2011).

\section{Notas}

1 Informação do Banco Nacional de Dados do Poder Judiciário.

2 Relatório "Justiça em Números 2010", sistematizado pelo Departamento de Pesquisas Judiciárias do CNJ e disponível em www.cnj.jus.br.

3 Na expressão cunhada pelo constitucionalista norte-americano Alexander Bickel, que considerava o Judiciário o órgão de soberania menos perigoso ou o mais fraco por não ter condições para aplicar suas sentenças. Mas o seu insulamento, por outro lado, lhe garantia ótimas condições para interpretar os ditames constitucionais e eventualmente avaliar as ações do Executivo e do Legislativo.

4 Vide North, D. “The Role of Institutions in Economic Development," ECE Discussion Papers Series, UNECE, 2003, n², UNECE.

5 Vide Relatório ICJ Brasil - $3^{\circ}$ trimestre, p. 03. Disponível em: http://virtualbib.fgv.br/ dspace/handle/10438/7727. Acesso em: 21 mar. 2011.

6 Vide TAYlor (2007), p. 230.

7 A expressão pode receber um sentido de processo social e político, quando é usada para se referir à expansão do âmbito qualitativo de atuação do sistema judicial, do caráter dos procedimentos de que dispõem e, ainda do aumento do número de processos nos tribunais. A judicialização também pode ser tomada como um processo objetivo utilizado para defender propostas de mudança na organização do Judiciário ou na cultura jurídica, considerada defasada face às novas necessidades sociais. Vide Maciel e Koerner, 2002, p.115-116.

8 Vide Relatório "100 maiores litigantes“ publicado pelo CNJ em março de 2011. Disponível em: http://www.cnj.jus.br/images/pesquisas-judiciarias/pesquisa_100_maiores_litigantes.pdf. Acesso em: $1^{\circ}$ jun.2011. 


\section{Referências bibliográficas}

Bucci, Maria Paula Dallari. Políticas públicas: reflexões sobre o conceito jurídico. In: Bucci, Maria Paula Dallari (Org.). O conceito de política pública em direito. São Paulo: Saraiva, 2006, p. 1-49.

Canon, Bradley; Johnson, Charles. Judicialpolicies: implementation and impact. $2^{\text {nd }}$ Edition. Washington D.C.: CQ Press, 1998.

Carneiro, Carla Bronzo Ladeira. Conselhos de Políticas Públicas: desafios para sua institucionalização. In: Saravia, Enrique e Ferrarezi, Elisabete (Org.) Coletânea Políticas Públicas. Brasília: ENAP, 2007. v.2. p. 149-166.

Castelar Pinheiro, Armando. Judiciário e Economia no Brasil. São Paulo: Sumaré, 2000.

Castro, Marcos Faro. O Supremo Tribunal Federal e a Judicialização da Política. Revista Brasileira de Ciências Sociais, v. 12, n. 34, jun. 1997. Disponível em: www.anpocs.org.br/ portal/publicacoes/rbcs_00_34/rbcs34_09.htm. Acesso em: 26/03/2011.

Costa, Flávio Dino de Castro e. O Conselho Nacional de Justiça: competências e aspectos processuais. In: Freitas, Wladimir Passos de (Coord.). Direito e Administração da Justiça. Curitiba: Juruá, 2009, p. 77 a 95.

CunHA, Armando. A busca de maior vitalidade da gestão nas organizações do poder Judiciário. Cadernos FGV Projetos, Rio de Janeiro, Ano 5, n. 2, p. 46, p. 46-52 mai./jun. de 2010.

Fabri, Marco; Langbroek, Phillip. The challenge for change for judicial systems: developing a public administration perspective. Amsterdam: IOS Press, 2000.

FALCÃo, Joaquim. O múltiplo Judiciário. In: SADEK, Maria Tereza (Org.). Magistrados, uma imagem em movimento. Rio de Janeiro: FGV Editora, 2006. p. 115 a 137.

Garapon, Antoine. O juiz e a democracia: o guardião das promessas. Rio de Janeiro: Revan, 2001.

Garoupa, Nuno; Ginsburg, Tom. The comparative law and economics of judicial councils. Berkeley Journal of International Law, v. 27, n.1, p. 52-82, 2008.

Gomes, Conceição. O tempo dos tribunais: um estudo sobre a morosidade da justiça. Coimbra: Coimbra Editora, 2003.

Maciel, Débora Alves; Koerner, Andrei. Sentidos da judicialização da política: duas análises. Revista Lua Nova, n. 57, p.113-133, 2002. Disponível em: www.scielo.br/pdf/ln/n57/ a06n57.pdf. Acesso em: 12/08/2011.

Massa-Arzabe, Patrícia Helena. Dimensão jurídica das políticas públicas. In: Bucci, Maria Paula (org.). Políticas Públicas: Reflexões sobre o conceito jurídico. São Paulo: Saraiva, 2006. P. 51 a 74.

Renault, Sérgio R. Tamm. A reforma do Poder Judiciário sob a ótica do governo federal. Revista do Serviço Público, Brasília, ENAP, v. 56, n.2, p. 127-136, abr. a mar. de 2005.

SAntos, Boaventura de Sousa. Por uma revolução democrática da justiça. São Paulo: Cortez, 2007.

Taylor, Matthew M. O Judiciário e as Políticas Públicas no Brasil. Dados, Rio de Janeiro, IUPERJ, v. 50, n. 2, p. 229 a 257. 
SubIRATS, Joan. Definición del problema. Relevancia pública y formación de la agenda de actuación de los poderes públicos. In: SAravia, Enrique e Ferrarezi, Elisabete (Org.) Coletânea Políticas Públicas. Brasília: ENAP, 2007. v.1. p.199-218.

Werneck Viana, Luiz et. al. A judicialização da política e das relações sociais no Brasil. Rio de Janeiro: Revan, 1999. 


\section{Resumo-Resumen-Abstract}

\section{Políticas Judiciárias no Brasil: o Judiciário como autor de políticas públicas Jeovan Assis da Silva e Pedro de Abreu e Lima Florêncio}

O artigo salienta a importância de se incorporar o Poder Judiciário nos estudos de políticas públicas, sobretudo a partir do foco sobre as ações desenvolvidas pelos tribunais e, principalmente, pelo Conselho Nacional de Justiça. Devido ao papel estratégico do Judiciário nas democracias contemporâneas, urge-se compreender melhor as transformações experimentadas no Brasil e em diversos países, sobretudo a partir do fortalecimento dos conselhos encarregados de prover maior accountability, coordenação e controle para os sistemas judiciais. A partir das especificidades da Justiça brasileira, o CNJ assume um papel central de concepção e elaboração de políticas para incrementar a atuação jurisdicional e torná-la mais célere, efetiva e responsiva às necessidades sociais. Propõe-se então o aprofundamento da análise e do debate críticos sobre os fundamentos, dinâmica, construção institucional, limites e potencialidades dos processos relacionados à formulação e à implementação de políticas judiciárias.

Palavras-chave: políticas públicas; Judiciário; Conselho Nacional de Justiça (CNJ)

\section{Políticas judiciarias en Brasil: E1 Judiciario como autor de políticas públicas Jeovan Assis da Silva y Pedro de Abreu e Lima Florêncio}

Este artículo muestra la importancia de incorporarse el Poder Judiciario en los estudios sobre políticas públicas, principalmente a partir del enfoque en las acciones desarrolladas por los tribunales y por el Consejo Nacional de Justicia. Por su papel estratégico en las democracias contemporáneas es importante comprender mejor las transformaciones ocurridas en Brasil y varios otros países, principalmente a partir del fortalecimiento de los consejos encargados de conferir más accountability, coordinación y control de los poderes judiciarios. A partir de las particularidades de la Justicia brasileña, el CNJ asume un rol central de concepción y elaboración de políticas para perfeccionar la actuación jurisdiccional y tornarla más rápida, efectiva y responsiva a las necesidades sociales. Se propone, entonces, la profundización del análisis y del debate críticos sobre los fundamentos, la dinámica, la construcción institucional, los límites y las potencialidades de los procesos relacionados a la formulación y implementación de políticas judiciarias.

Palabras clave: políticas públicas; Poder Judiciario; Consejo Nacional de Justicia.

\section{Public judicial policies in Brazil: The Judiciary as a public policy maker Jeovan Assis da Silva and Pedro de Abreu e Lima Florêncio}

The article stresses the importance of incorporating the Judicial Branch in public policy studies, especially with a focus on the Brazilian National Council of Justice's and the court's initiatives. In view of the Judiciary's strategic role in modern democracies, it is particularly important to understand the operated changes within this branch after the consolidation of National Councils, which are responsible for providing greater accountability, coordination and control for the Judicial Branches. Considering the particularities of the Brazilian Judiciary, the National Council of Justice assumes a pivotal role in the elaboration of public policies to enhance judicial services, contributing for its effectiveness, rapidity and responsiveness to social demands. It is therefore relevant to increase the analysis and to stimulate debates about the essential aspects, the dynamics, institutional foundations, limits and potentialities of the procedures related to the implementation of judicial policies.

Keywords: public policies; Judicial branch; National Council of Justice. 
Jeovan Assis da Silva

Mestre e bacharel em Relações Internacionais pela Universidade de Brasília (UnB) e bacharel em Direito pelo Centro Universitário do Distrito Federal (UDF). Especialista em Políticas Públicas e Gestão Governamental, exerceu cargos de assessoria técnica na Escola Nacional de Administração Pública (ENAP) e no Ministério da Fazenda, bem como trabalhou como pesquisador do Departamento de Pesquisas Judiciárias do Conselho Nacional de Justiça (CNJ). Atualmente trabalha na Secretaria de Direitos Humanos da Presidência da República. Contato: jvnsilva@gmail.com

Pedro de Abreu e Lima Florêncio

Mestre em Direito Econômico Internacional (Universidade de Warwick, Reino Unido) e bacharel em Direito pelo Centro Universitário de Brasília (Uniceub) e em Economia pela Universidade de São Paulo (USP). Especialista em Políticas Públicas e Gestão Governamental, foi coordenador de investigação de práticas anticompetitivas e coordenador de defesa comercial do Ministério da Fazenda. Atualmente é diretor de projetos do Departamento de Pesquisas Judiciárias do CNJ.

Contato: pedro.abreu.lima.florencio@gmail.com 